\title{
Oral Mucoceles and Ranulas May Be Part of Initial Manifestations of HIV Infection
}

\author{
Kabunda Syebele and Kurt-w Bütow
}

\begin{abstract}
It is well documented and generally accepted that enlargement of parotid salivary glands, as part of HIV-related salivary gland diseases (HIV-SGD), may be the initial symptoms/manifestations of the HIV infection. Oral mucoceles and ranulas are also frequently described as oral manifestations, in association with HIV infection. However, little is known about these latter lesions as being the initial symptoms indicative of an HIV infection. This prospective study has investigated the possibility that oral mucoceles in general, and ranulas in particular, could be the initial symptoms of an underlying and undiagnosed HIV infection. A total of 50 patients including cases of oral mucoceles and ranulas were consulted in a tertiary referral hospital set up. Nineteen (63\%) out of 30 HIV-positive patients presenting with oral mucoceles/ranulas, did not know their HIV status at the first consultation. Oral mucoceles/ranulas were for these patients, the only motives for visiting the health facility, and they were also the only clinical identifiable features (symptoms). Oral mucoceles and ranulas should, in the context of HIV-salivary gland diseases, be considered as initial symptoms and early manifestations of HIV infection. Routine HIV testing in all patients with oral mucoceles and ranulas is, according to this study, justified and should be recommended.
\end{abstract}

\section{Introduction}

$\mathbf{P}$ AROTID SALIVARY GLAND ENLARGEMENT has been the best and most commonly described HIV-related salivary gland diseases. Oral mucoceles and ranulas were not considered among the most frequent lesions associated with HIV infection in pediatric and adult patients. ${ }^{1-3}$ However, ranulas, as a type of oral mucoceles specifically arising from the floor of the mouth, have been increasingly mentioned in the literature, in association with HIV-infected patients. ${ }^{4-8}$

The frequent association of HIV infection with oral lesions including parotid glands enlargement, has not only compounded the HIV-related stigma issue, but has also led to a situation where HIV testing is routinely requested by health practitioners. ${ }^{9,10}$ It is generally accepted that enlargement of parotid glands, as part of what is traditionally termed as HIV-related salivary gland disease (HIV-SGD), may be the initial symptom of an undiagnosed HIV infection. ${ }^{10,11}$ It is not, therefore, unusual for HIV testing to be requested on the background of parotid gland enlargement alone. However, little is known in general about oral mucoceles, and in particular about ranulas, as an initial symptom of HIV infection.

This article presents a situation where a number of otherwise "healthy" patients are diagnosed and made aware for the first time, of their HIV-positive status, following a consultation for oral mucoceles or ranulas.

\section{Materials and Methods}

The Department of MaxilloFacial and Oral Surgery at the University of Pretoria has consulted 50 cases of oral mucoceles and ranulas. Different types (Figs. 1, 2, and 3), as well as sites of oral mucoceles and ranulas were recorded: lip, floor of the mouth, with or without cervical component (plunging ranulas), or cervical alone without an intra oral component. The patients were divided in two groups. The first group included patients with known HIV status. The second group included patients with undiagnosed and unknown HIV status at the time of the consultation.

The assessment of the overall health for patients, who did not know their HIV status, was based on the medical history. Special attention was focused on any clinical elements that could raise suspicion of an undiagnosed HIV infection. History of PTB, presence of skin lesions, enlargement of parotid glands, and history of herpes zoster were some of the excluding clinical features. Furthermore, special attention was given to the identification of any previous history of trauma or surgery in the oral cavity, including tooth extraction. An incisional or excisional biopsy was performed, and histological reports

Department of Maxillo-Facial and Oral Surgery, University of Pretoria, Pretoria, South Africa. 


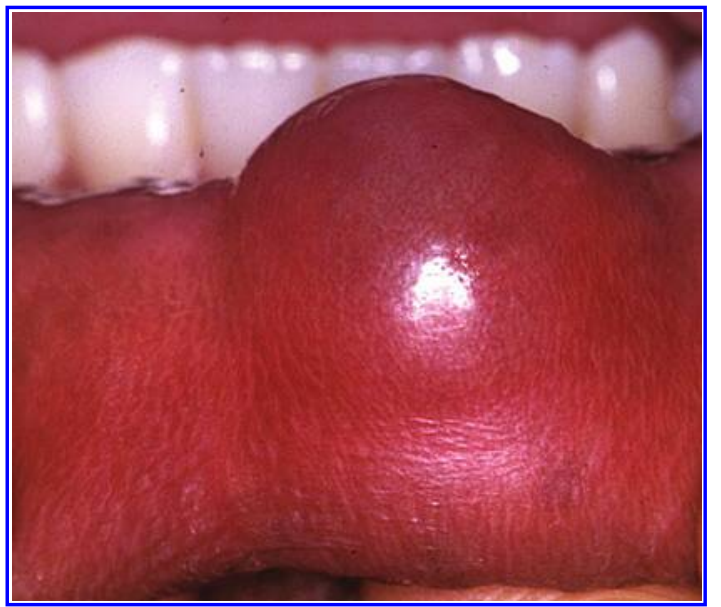

FIG. 1. A small oral mucocele on the lower lip. (Color image can be found at www.liebertonline.com/aid).

confirming an extravasation phenomenon cyst were obtained for the histological diagnosis of oral mucocele or ranula.

A HIV Ag (p24)/Ab combination assay was used to establish patients HIV status. A confirmation test was also routinely performed on all cases.

\section{Results}

Demographic data of 50 cases of oral mucoceles are presented in Table 1. A total of 36 female and 14 male patients were consulted. The majority of cases with mucoceles/ranulas, $31(62 \%)$ out of 50 patients were younger than 20 years of age, of which $15(30 \%)$ out of 50 were under 10 years of age. The distribution of cases of oral mucoceles and ranulas between HIV-positive and HIV-negative patients is recorded in Table 2. Two patients could not be tested because no informed consent was given. From the remaining 48 patients tested for HIV infection, 33(68.7\%) were HIV positive, of which $10(30 \%)$ out of 33 were under 10 years of age.

From a total of 15 patients diagnosed HIV-negative, two patients knew their HIV status, and 13 patients did not know their HIV status prior to the consultation for the problem concerning their oral mucoceles/ranulas. In

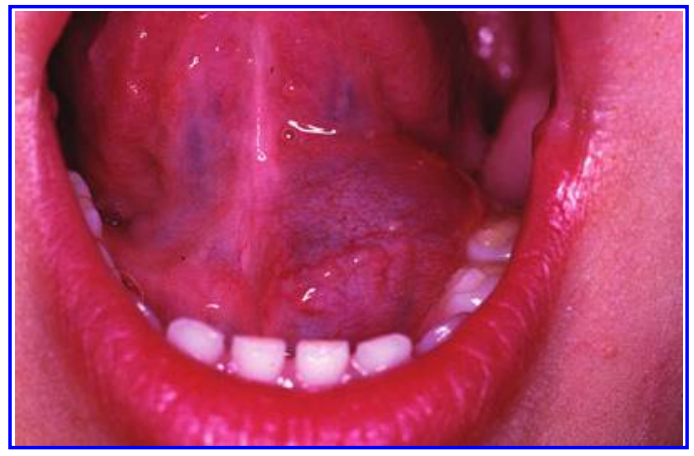

FIG. 2. Typical presentation of oral mucoceles (ranula) in the floor of the mouth, with the Wharton duct running on the surface of the cystic lesion. (Color image can be found at www.liebertonline.com/aid).

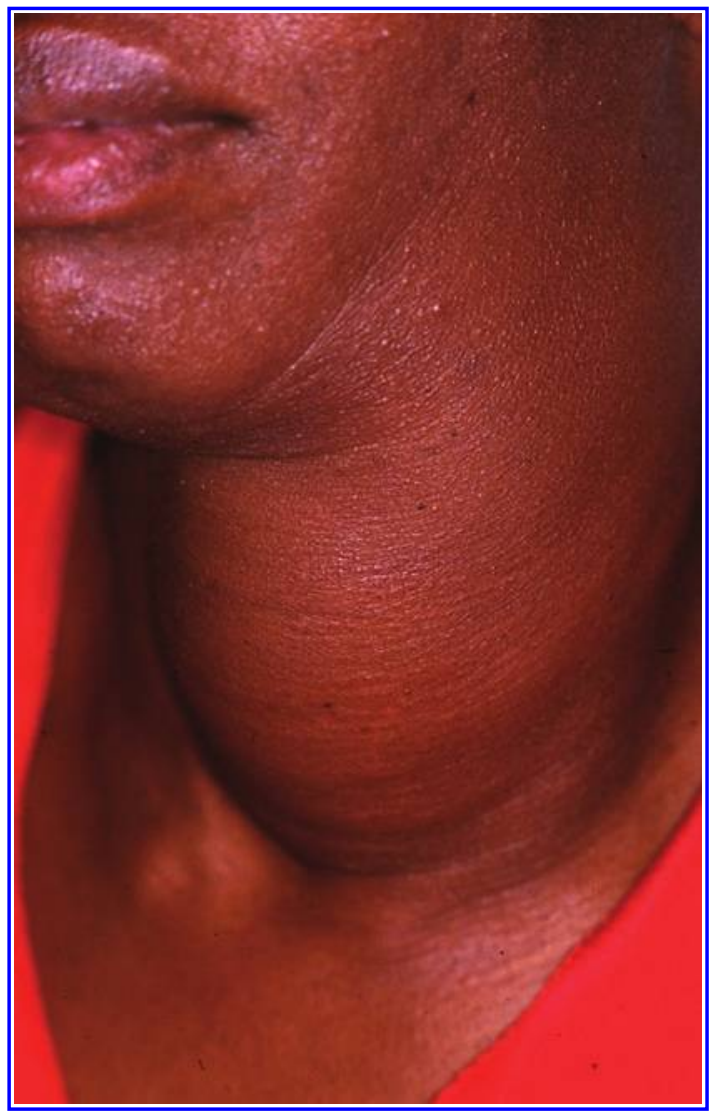

FIG. 3. A huge cystic lesion which is, in fact, a cervical component of a plunging ranula comprising a small intra oral lesion also. (Color image can be found at www .liebertonline.com/aid).

the group of 33 patients diagnosed HIV-positive, eleven knew about their HIV status, however, the remaining 22 were, according to their medical history, undiagnosed HIV-positive patients prior to the first consultation for the problem concerning oral mucoceles/ranulas. In this latter group of 22 patients, three patients were excluded, as HIV infection could clinically be suspected during the first visit, based on the PTB history and/or the presence of skin lesions. These patients were most probably aware of their HIV status, although they did not want to disclose it. Oral mucocele or ranula would not be thus the unique and discovering symptom of an underlying HIV infection for these three patients. Therefore, only $19(63 \%)$ out of 30 HIV-positive patients were considered as "healthy" and were discovered to be HIV positive only after the first consultation for their oral mucoceles/ranulas.

Table 1. Demographic Data of 50 Patients Presenting With Oral Mucoceles

\begin{tabular}{lrrrccc}
\hline Age Sex & $0-10$ & $11-20$ & $21-30$ & $31-40$ & $41-50$ & Total \\
\hline Male & 5 & 7 & 0 & 2 & 0 & 14 \\
Female & 10 & 9 & 9 & 6 & 2 & 36 \\
Total & 15 & 16 & 9 & 8 & 2 & 50 \\
\hline
\end{tabular}


Table 2. Distribution of HiV Status by Age Groups

\begin{tabular}{lcccccc}
\hline Age HIV status & $0-10$ & $11-20$ & $21-30$ & $31-40$ & $41-50$ & Total \\
\hline HIV(+) & 10 & 6 & 7 & 8 & 2 & 33 \\
HIV(-) & 5 & 9 & 1 & 0 & 0 & 15 \\
Total & 15 & 15 & 8 & 8 & 2 & 48 \\
\hline
\end{tabular}

Table 3. Comparison Between HIV Status and Various Clinical Sites of Oral Mucoceles/Ranulas

\begin{tabular}{lccccc}
\hline $\begin{array}{l}\text { Site: HIV } \\
\text { Status }\end{array}$ & Lip & $\begin{array}{c}\text { Mouth } \\
\text { floor alone }\end{array}$ & $\begin{array}{c}\text { Cervical } \\
\text { alone }\end{array}$ & $\begin{array}{c}\text { Mouth floor } \\
\text { and cervical }\end{array}$ & Total \\
\hline HIV (+) & 1 & 20 & 1 & 11 & 33 \\
HIV(-) & 4 & 11 & 0 & 0 & 15 \\
Total & 5 & 31 & 1 & 11 & 48 \\
\hline
\end{tabular}

In Table 3 different clinical sites of oral mucoceles/ranulas are recorded in relation to the HIV status of patients. A high number of plunging ranulas were recorded: 11 (33\%) out of 33 HIV-positive patients compared to 0 cases in the HIV-negative group.

\section{Discussion}

Oral mucoceles, including ranulas, are common lesions of the oral cavity, and their development is specifically linked to minor salivary glands, and some major salivary glands (sublingual and submandibular glands). Direct trauma or surgical procedures to the oral cavity soft tissues has been considered as a major etiological factor. ${ }^{12,13}$ The role of HIV / AIDS as an etiological factor of oral mucocele and ranula is not clearly established. However, ranula has been linked to HIV infection in the literature. ${ }^{4,6,7}$ In other words, oral mucoceles and ranulas might be considered, in the context of HIV-related salivary gland diseases, as part of lesions most commonly associated with HIV infection. ${ }^{4-7}$ The exact prevalence of oral mucoceles among HIV-infected patients is not known. It has, however, been suggested that oral mucoceles and ranulas are frequent in pediatric HIV-positive patients. ${ }^{4}$

This study found that $33(68.75 \%)$ out of 48 cases of oral mucoceles were HIV-positive. It was also found that 16 (48.4\%) out of $33 \mathrm{HIV}$-positive cases of oral mucoceles were patients under the age of 20 years. This is in line with what has been reported about ranulas in the existing literature. ${ }^{4}$

HIV testing is not a routine request in cases of oral mucoceles and ranulas. Little is also reported about oral mucoceles or ranulas being the first symptoms and unique motives for consultation in HIV-infected patients. In this study, 19 (63.3\%) out of $30 \mathrm{HIV}$-positive patients, presenting with oral mucoceles and ranulas were recorded. These patients did not know their HIV status at the time of their first consultation. Oral mucoceles and ranulas were the initiating reason for consultation.

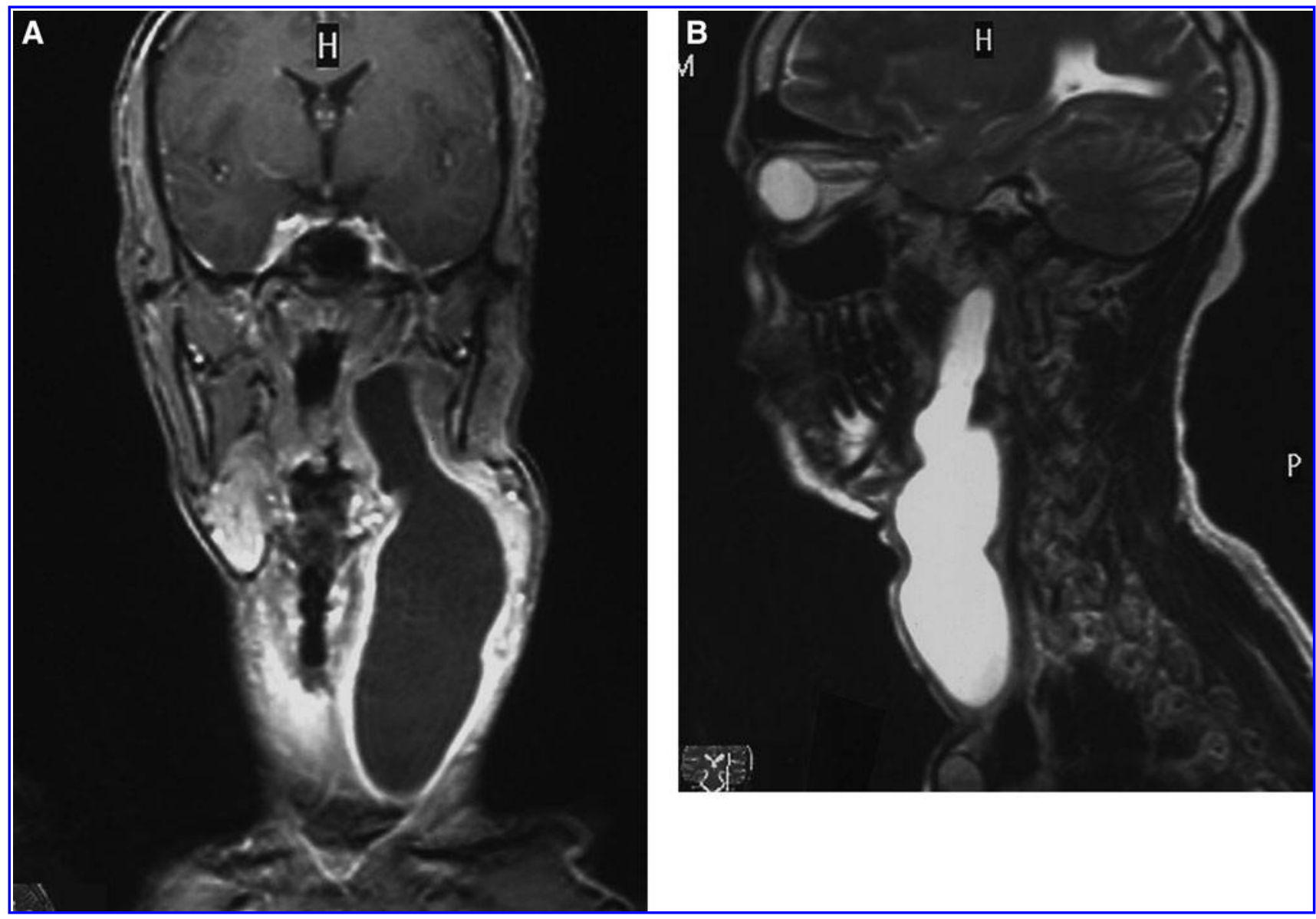

FIG. 4 MRI, (A)T1 and (B)T2- weighted, showing the extension of a case of plunging ranulas in HIV-infected patient in Figure 3. 
The HIV-positive status was only established in the subsequent work-out process.

Although HIV-testing policies vary from country to country, a common ground has, however, emerged and may be summarized as follows: not withstanding the confidentiality aspect, routine HIV testing must be offered to all patients visiting any health facility, irrespective of the reason of their visit ("Provider Initiated or Voluntary Testing and Counseling" [PIVTC]). Patients remain, however, entitled to their right to decline such an offer ("The Opt-out Approach"). 9,14,15 Furthermore, it is generally accepted that the presence or development of oral lesions, as well as those from salivary glands, provide a strong indication of the possibility of an underlying HIV infection. ${ }^{10}$ Based on the importance of oral lesions in the diagnosis of HIV infection (i.e., parotid gland enlargement), there is, therefore, a rational ground for routine HIV testing in all cases with oral mucoceles or ranulas.

Oral lesions most frequently associated with HIV infection such as oral candidosis, gingivitis (ANUG), oral Kaposi sarcoma, herpes zoster, and enlargement of parotid glands have already provided a major platform for oral health care providers to contribute to the prevention and management of HIV infection. The results from this study found that $68.75 \%$ (33 out of 48 patients) cases of oral mucoceles/ranulas were HIV positive. Some authors would argue that this kind of results must be considered in the overall context of HIV prevalence in the Southern Africa region. ${ }^{7}$ Nevertheless, the argument does not completely remove the need to include in the list of oral lesions commonly associated with HIV infection, oral mucoceles and ranulas. These latter lesions need also to be considered as early clinical features of the HIV infection. In this study, 11 (33.3\%) cases had a plunging ranula recorded from $33 \mathrm{HIV}$-positive patients, with none in HIV-negative group. The study has taken note of this difference but the small size of the sample does not allow any statistic conclusion on these results. However, should one consider this appearance as an indication of a possible aggressiveness of ranulas in HIV-positive patients (Figs. 4A and 4B)? This fact needs to be established by larger sample studies.

\section{Conclusion}

The clinical diagnosis of oral mucoceles or ranulas, and their surgical management, is not influenced by patient HIV status. Nonetheless, the increased access to antiretroviral drugs, combined with the improved knowledge about the benefit from early initiation of this therapy, has made the knowledge of HIV status almost a necessity. The request for routine HIV testing in case of oral mucoceles or ranulas may once again be emphasized because of its potential for early HIV-infection diagnosis. The most important factor associated with HIV-related morbidity and mortality remains indeed, influenced by late HIV infection diagnosis. ${ }^{9}$

The importance of various oral manifestations in HIVinfected patients is well recognized. It does appear through this study that oral mucoceles and ranulas need also to be considered, along with the parotid gland enlargement, as part of the HIV-related salivary gland diseases. Oral mucoceles and ranulas need also to be considered not only as lesions strongly associated with HIV infection, but also as initial symptoms or early manifestation of HIV infection. Routine HIV testing for all patients with oral mucoceles and ranulas may, therefore, be justified and recommended.

\section{Author Disclosure Statement}

No competing financial interests exist.

\section{References}

1. EC-Clearinghouse. EC-Clearinghouse on oral problems related to HIV infection and WHO collaborating centre on oral manifestation of the immunodeficiency virus. Classification and diagnostic criteria for oral lesions in HIV infection. J Oral Pathol Med 1993;22:289-291.

2. Ramos-Gomez FJ, Flaitz C, Catapano P, Murray P, Milnes $\mathrm{AR}$, and Dorenbaum A. Classification, diagnostic criteria, and treatment recommendations for orofacial manifestations in HIV-infected pediatric patients. Collaborative workgroup on oral manifestations of pediatric HIV infection. J Clin Pediatr Dent 1999;23:85-96.

3. Frezzini C, Leao JC, and Porter S. Current trends of HIV disease of the mouth. J Oral Pathol Med 2005;34:513-531.

4. Chidzonga MM and Rusakaniko S. Ranula: Another HIV/ AIDS associated oral lesion in Zimbabwe? Oral Dis 2004;10:229-232.

5. Chidzonga MM and Mabomva L. Ranula: Experience with 83 cases in Zimbabwe. J Oral Maxillofac Surg 2007;65:79-82.

6. Flaitz CM and Hicks MJ. Mucocele and ranula. Available from URL: http://emedicine.medscape.com/article/1076717overview.

7. Baurmash HD. Ranula and HIV: An explanation of their relationship. J Oral Maxillofac Surg 2007;65:1670-1671.

8. Hom JM, Morisseau S, Pape JW, and Fitzgerald DW. Oral manifestations of HIV in Haitian children and adolescents. IADR/AADR/CADR $87^{\text {th }}$ General session and exhibition (April 1-4, 2009).

9. British HIV association, British association for sexual health and HIV, British infection society. UK national guidelines for HIV testing, 2008.

10. Coogan MM, Greenspan J, and Challacombe JS. Oral lesions in infection with human immunodeficiency virus. Bull World Health Org 2005;83:700-706.

11. Dave SP, Pernas FG, and Roy S. The benign lymphoepithelial cyst and classification system for lymphocytic parotid gland enlargement in the pediatric HIV population. Laryngoscope 2007;117:106-113.

12. CDC. Revised recommendations for HIV testing of adults, adolescents, and pregnant women in health care settings. MMWR 2006;55(RR14):1-17.

13. World Health Organization/UNAODS, 2007. Guidance on provider-initiated HIV testing and counseling in health facilities. Geneva: World Health Organization/UNAIDS.

14. Zhao YF, Jia Y, Chen XM, and Zhang WF. Clinical review of 580 ranulas. Oral Surg Oral Med Oral Pathol Oral Radiol Endod 2004;98:281-287.

15. Neville BW, Damm DD, Allen CM, and Bouquot JE. Salivary gland pathology. In: Oral and Maxillofacial Pathology. $3^{\text {rd }}$ ed. Saunders, St Louis 2009, pp. 453-459.

Address correspondence to: Dr. Kabunda Syebele Maxillo-Facial and Oral Surgery University of Pretoria P O Box 1266 Pretoria 0001 South Africa

E-mail: kabunda.syebele@up.ac.za 
This article has been cited by:

1. Kabunda Syebele, Thifhelimbilu I. Munzhelele. 2013. The potential impact of highly active antiretroviral therapy on the treatment and epidemiology of ranula in human immunodeficiency virus-positive patients. Oral Surgery, Oral Medicine, Oral Pathology and Oral Radiology 116:1, e32-e36. [CrossRef]

2. Mohammed Nadershah, Andrew Salama. 2012. Removal of Parotid, Submandibular, and Sublingual Glands. Oral and Maxillofacial Surgery Clinics of North America 24:2, 295-305. [CrossRef]

3. Adriane Kamulegeya, Samuel Moses Okello. 2012. Ranulas: possible signs for HIV/AIDS? 1 year Ugandan descriptive study. Acta Odontologica Scandinavica 70:2, 149-153. [CrossRef]

4. Kabunda Syebele, Kurt-W. Bütow, Lynne Webber, Samuel O. Manda. 2011. Quantification of HIV-1 viral load in the fluid of ranulas in HIV-positive patients. Oral Surgery, Oral Medicine, Oral Patbology, Oral Radiology, and Endodontology 111:6, 715-719. [CrossRef] 